\title{
Recurrent spontaneous pneumothoraces and vaping in an 18-year-old man: a case report and review of the literature
}

\author{
Alex Bonilla', Alexander J. Blair², Suliman M. Alamro ${ }^{3}$, Rebecca A. Ward ${ }^{2,4}$, Michael B. Feldman ${ }^{2,3}$, \\ Richard A. Dutko ${ }^{2,4}$, Theodora K. Karagounis ${ }^{2}$, Adam L. Johnson², Erik E. Folch ${ }^{2,3}$ and Jatin M. Vyas ${ }^{1,2,4^{*}}$
}

\begin{abstract}
Background: Primary spontaneous pneumothorax is a common disorder occurring in young adults without underlying lung disease. Although tobacco smoking is a well-documented risk factor for spontaneous pneumothorax, an association between electronic cigarette use (that is, vaping) and spontaneous pneumothorax has not been noted. We report a case of spontaneous pneumothoraces correlated with vaping.

Case presentation: An 18-year-old Caucasian man presented twice with recurrent right-sided spontaneous pneumothoraces within 2 weeks. He reported a history of vaping just prior to both episodes. Diagnostic testing was notable for a right-sided spontaneous pneumothorax on chest X-ray and computed tomography scan. His symptoms improved following insertion of a chest tube and drainage of air on each occasion. In the 2-week follow-up visit for the recurrent episode, he was asymptomatic and reported that he was no longer using electronic cigarettes.
\end{abstract}

Conclusions: Providers and patients should be aware of the potential risk of spontaneous pneumothorax associated with electronic cigarettes.

Keywords: Primary spontaneous pneumothorax, Pulmonary disease, Vaping, Electronic cigarettes

\section{Background}

Primary spontaneous pneumothorax impacts approximately 20 out of 100,000 males and 6 out of 100,000 females annually [1]. Pneumothorax is characterized by the accumulation of air in the pleural space, often caused by ruptured subpleural blebs or bullae [2-4]. Risk factors that contribute to the development of spontaneous pneumothorax include tobacco smoking, age (adolescents and young adults), thin stature, and male sex. Furthermore, recurrent spontaneous pneumothoraces occurs in $20-60 \%$ of patients [5]. Age, gender, tobacco smoking habits, pneumothorax size, low body mass index (BMI), and treatment modality have been suggested to contribute to recurrent spontaneous pneumothoraces $[4,6]$. Although cigarette smoking is a well-established risk factor

\footnotetext{
* Correspondence: JVYAS@mgh.harvard.edu

'Department of Medicine, Harvard Medical School, 25 Shattuck Street, Boston, MA 02115, USA

2Department of Medicine, Massachusetts General Hospital, 55 Fruit Street Boston, MA 02114, USA

Full list of author information is available at the end of the article
}

for spontaneous pneumothorax [7-9], little is known about the contribution of electronic cigarettes to the development of spontaneous pneumothorax.

The use of electronic cigarettes has rapidly increased over the past decade, in particular among adolescents and young adults. Approximately $20.8 \%$ of high school students and $4.8 \%$ of adults age $18-34$ years currently use e-cigarettes (also known as electronic cigarettes) [10]. Electronic cigarettes (that is, vapes) are portable, battery-powered devices that heat a complex liquid mixture containing nicotine to produce a vapor that users inhale. Many devices rely on replaceable liquid "pods" that may contain propylene glycol, glycerol, benzoic acid, nicotine, and artificial flavors [11]. A recent study reported high nicotine concentrations of pods ranging from $21.8 \mathrm{mg} / \mathrm{mL}$ to $59.2 \mathrm{mg} / \mathrm{mL}$. These pods have considerably higher levels of nicotine per puff than older generation electronic cigarettes [12]. The long-term adverse health effects due to vaping are not well known, but several case reports have associated vaping with

(c) The Author(s). 2019 Open Access This article is distributed under the terms of the Creative Commons Attribution 4.0 International License (http://creativecommons.org/licenses/by/4.0/), which permits unrestricted use, distribution, and 
adverse respiratory, cardiovascular, neurological, and gastrointestinal health effects [13-17]. Unfortunately, it remains unknown whether vaping is a risk factor for spontaneous pneumothorax. Here, we describe an 18-year-old man with recurrent spontaneous pneumothoraces within 2 weeks that were temporally correlated with vaping.

\section{Case presentation}

An 18-year-old Caucasian man presented in January 2019 to our Emergency Department (ED) for evaluation of sudden-onset right-sided chest pain while sleeping. He reported waking up with acute right-sided pleuritic chest pain underneath his ribs with radiation to his right scapula, which was made worse with inspiration and movement. He denied classic triggers, including excessive coughing, recent respiratory tract infection, or trauma prior to the onset of pain. However, he reported multiple episodes of vaping daily and rare intermittent marijuana use, but denied cigarette smoking or use of smokeless tobacco. He had no past medical or surgical history, history of vision changes, heart problems, or joint laxity. In addition, there was no family history of Marfan syndrome or lung disease. He reported no current medications, cigarette smoking, or alcohol consumption.

A physical examination revealed a height and weight of $54.9 \mathrm{~kg}$ and $180 \mathrm{~cm}$, respectively with decreased breath sounds over his right lung. His calculated BMI had an underweight BMI of $16.9 \mathrm{~kg} / \mathrm{m}^{2}$. His vital signals were notable for a temperature of $36.4{ }^{\circ} \mathrm{C}$, heart rate of 64 , blood pressure of $112 / 59 \mathrm{mmHg}$, respiratory rate of 19 , and oxygen saturation of $95 \%$. A neurological examination revealed he was alert and oriented to person, place, and time, and he moved all extremities equally. The remainder of the neurologic examination was non-focal. Laboratory examinations were all normal (Table 1 ).

A chest X-ray (CXR) obtained in our ED demonstrated a large right-sided pneumothorax with evidence of tension (Fig. 1a). A chest tube was placed to suction with improvement in symptoms and our patient was admitted to the medicine service for further management. During admission, he received a lidocaine patch every 24 hours, acetaminophen $(650 \mathrm{mg})$ every 6 hours, and ketorolac tromethamine $(15 \mathrm{mg})$ every 6 hours, as needed. His pneumothorax resolved within the next few days and the chest tube was removed in a stepwise fashion. His presentation at the time was attributed to his body habitus. He was encouraged to quit vaping. He was scheduled for a follow-up CXR 2 weeks after discharge.

One week after discharge, he presented again to our ED for sudden-onset right-sided pleuritic chest pain and shortness of breath. Upon being admitted for recurrent spontaneous pneumothoraces, he reported daily vaping after discharge, but no fever, chills, hemoptysis, cough,
Table 1 Laboratory examination for the both admissions

\begin{tabular}{|c|c|c|}
\hline & $\begin{array}{l}\text { First } \\
\text { admission }\end{array}$ & $\begin{array}{l}\text { Second } \\
\text { admission }\end{array}$ \\
\hline \multicolumn{3}{|l|}{ Metabolic parameters } \\
\hline Sodium (mmol/L) & 139 & 140 \\
\hline Potassium (mmol/L) & 3.6 & 3.8 \\
\hline Chloride (mmol/L) & 101 & 105 \\
\hline Carbon dioxide (mmol/L) & 27 & 23 \\
\hline BUN (mg/dL) & 16 & 11 \\
\hline Creatinine (mg/dL) & 1.06 & 0.91 \\
\hline Glucose (mg/dL) & 96 & 98 \\
\hline Albumin (g/dL) & 4.5 & 4.2 \\
\hline Bilirubin (direct) (mg/dL) & 0.3 & $<0.2$ \\
\hline Bilirubin (total) (mg/dL) & 1.6 & 0.7 \\
\hline Total protein (g/dL) & 6.9 & 6.9 \\
\hline $\begin{array}{l}\text { Alanine aminotransferase (SGPT) (U/ } \\
\text { L) }\end{array}$ & 7 & 8 \\
\hline $\begin{array}{l}\text { Aspartate aminotransferase (SGOT) } \\
\text { (U/L) }\end{array}$ & 17 & 18 \\
\hline Alkaline phosphatase (U/L) & 55 & 46 \\
\hline \multicolumn{3}{|l|}{ Blood gases } \\
\hline $\mathrm{pH}$, venous & 7.35 & 7.34 \\
\hline $\mathrm{pCO}_{2}$, venous $(\mathrm{mmHg})$ & 52 & 51 \\
\hline \multicolumn{3}{|l|}{ Complete blood count } \\
\hline White blood cell count $(\mathrm{k} / \mu \mathrm{L})$ & 8.43 & 5.42 \\
\hline Platelet count $(\mathrm{k} / \mu \mathrm{L})$ & 192 & 189 \\
\hline Red blood cell count $(\mathrm{M} / \mu \mathrm{L})$ & 4.66 & 4.65 \\
\hline Hemoglobin (g/dL) & 14.7 & 14.5 \\
\hline Hematocrit (\%) & 42.7 & 42.7 \\
\hline Mean corpuscular volume (fL) & 91.6 & 91.8 \\
\hline Red cell distribution width (\%) & 12.5 & 12.4 \\
\hline \multicolumn{3}{|l|}{ Blood differential - absolute } \\
\hline Neutrophils & - & 2.48 \\
\hline Eosinophils & - & 0.13 \\
\hline Basophils & - & 0.04 \\
\hline Monocytes & - & 0.61 \\
\hline Lymphocytes & - & 2.16 \\
\hline
\end{tabular}

BUN blood urea nitrogen, $p \mathrm{CO}_{2}$ partial pressure of carbon dioxide, $\mathrm{SGOT}$ serum glutamic oxaloacetic transaminase, SGPT serum glutamic pyruvic transaminase

upper respiratory infection (URI) symptoms, trauma, or recent airplane travel. At this time, he described a 1.5year history of vaping with multiple devices. In addition, he again described occasional marijuana use, although marijuana had not been used between episodes of pneumothoraces.

On physical examination, his vital signs were within normal limits. His pupils were equal and reactive to light, without evidence of lens subluxation. His vital signals were notable for a temperature of $37.2{ }^{\circ} \mathrm{C}$, heart 
A

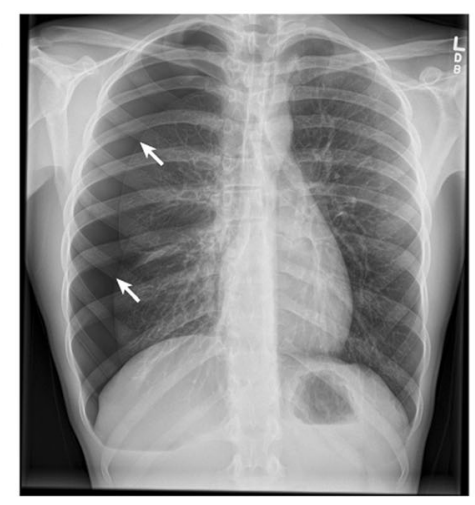

B

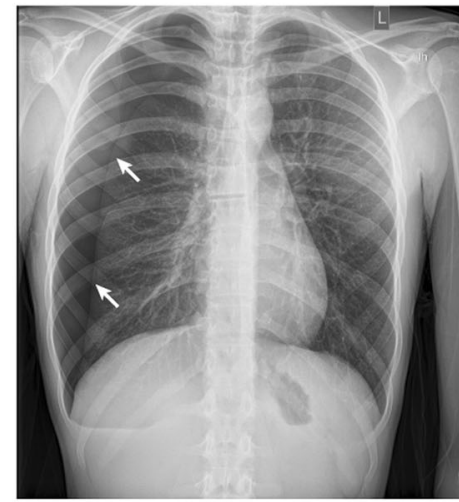

C

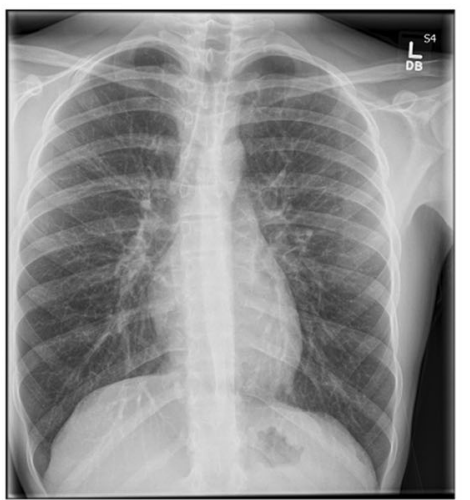

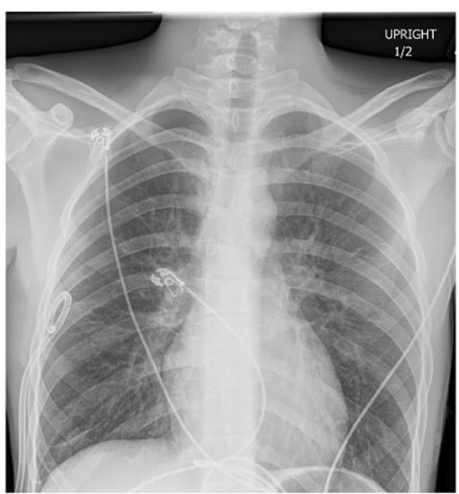
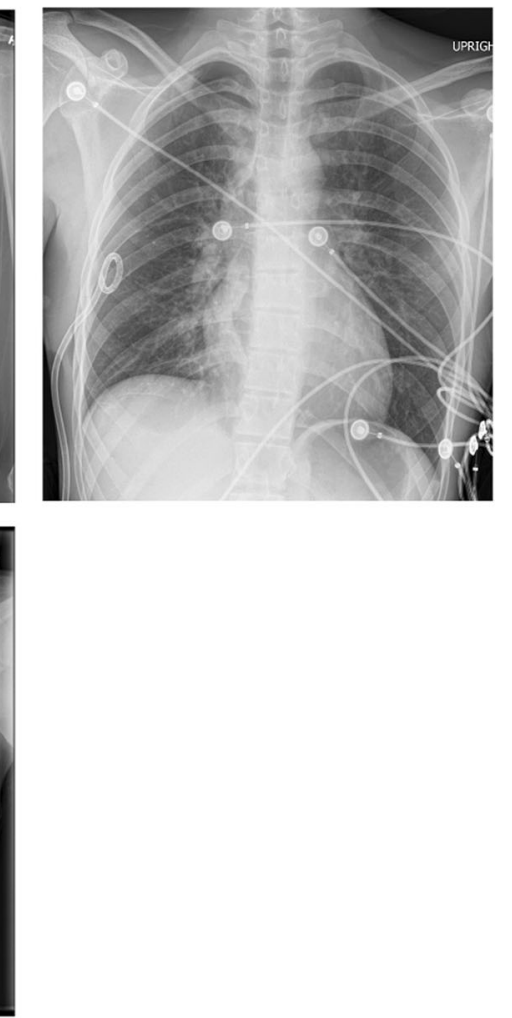

Fig. 1 Chest X-ray at initial presentation demonstrating a right-sided pneumothorax (arrow) and resolving right-sided pneumothorax after pigtail chest tube placement for initial (a) and recurrent (b) spontaneous pneumothorax. (c) Sustained recovery from recurrent spontaneous pneumothorax two weeks after the removal of chest tubes

rate of 63 beats/minute, blood pressure of 118/56 $\mathrm{mmHg}$, respiratory rate of 18 , and oxygen saturation of $97 \%$. A neurological examination revealed him to be alert and oriented to person, place, and time, and moving all extremities equally. The remainder of the neurologic examination was non-focal. Laboratory examinations were all normal (Table 1). He had normal heart sounds without murmurs, rubs, or gallops. A lung examination was notable for decreased breath sounds over the right posterior chest.

A CXR revealed the presence of a large recurrent right-sided spontaneous pneumothorax without evidence of significant mediastinal shift (Fig. 1b). A follow-up chest computed tomography $(\mathrm{CT})$ study without contrast after chest tube placement was notable for a small right residual pneumothorax with residual subsegmental atelectasis in his right lung and small right apical blebs (Fig. 2). The spontaneous pneumothorax was recategorized as secondary after noting apical blebs. He was treated with a pigtail chest tube after the initial CXR determined the presence of the spontaneous pneumothorax. His chest tube was removed when imaging confirmed durable resolution of the pneumothorax. His lungs were clear to auscultation bilaterally with symmetric breath sounds. During 

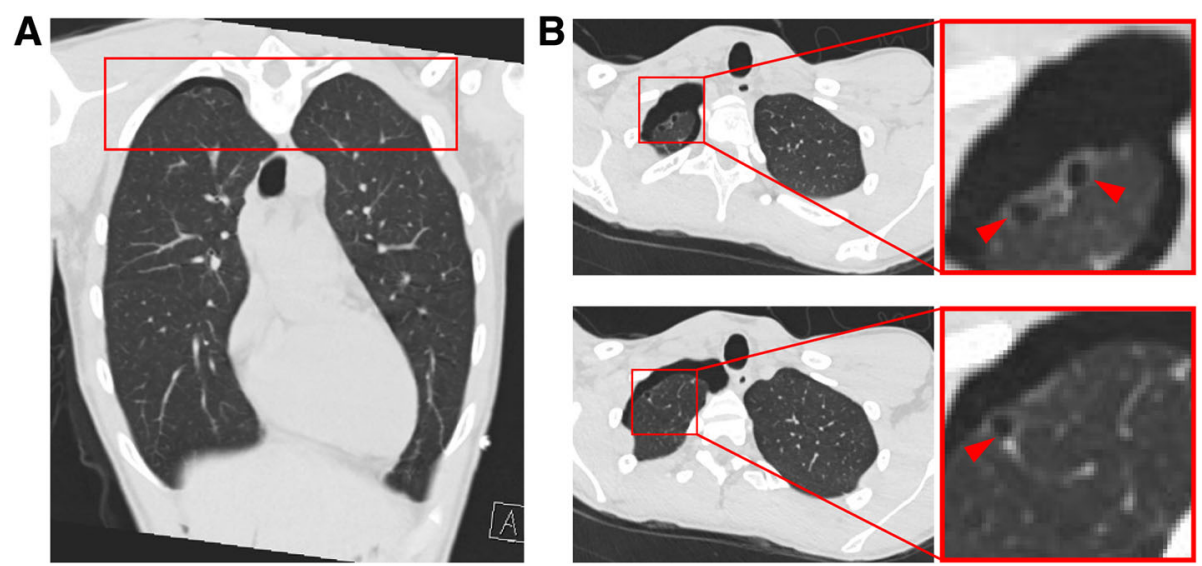

Fig. 2 Coronal (a) and axial (b) computed tomography slices showing apical blebs and residual pneumothorax. Axial cuts selected from the red box in panel A. Insets from axial images highlight the presence of apical blebs (arrowheads)

this second admittance, our patient was treated with lidocaine patch every 24 hours, acetaminophen $(650 \mathrm{mg})$ every 6 hours as needed, and ibuprofen $(600 \mathrm{mg})$ every 6 hours, as needed. A follow-up CXR 2 weeks after removal of the chest tubes confirmed resolution of the pneumothorax (Fig. 1c). At his follow-up appointment, he reported that he had quit using all e-cigarette products. A physical examination at this follow-up observed a temperature of $37.28^{\circ} \mathrm{C}$, heart rate 79 , blood pressure $110 / 72$, respiratory rate of 20 , and oxygen saturation of $96 \%$ on room air. On physical examination, he was in no acute distress with lungs clear to auscultation bilaterally and good excursion. No rales, wheezes, or rhonchi were noted on examination. In alignment with British Thoracic Society (BTS) guidelines [18], he was offered chemical pleurodesis and/or surgical options; however, he declined the procedure. Written informed consent was provided by our patient for the publication of this case report.

\section{Discussion and conclusions}

Here, we present a case of an 18-year-old patient who presented to our hospital for recurrent right-sided spontaneous pneumothoraces in which each episode occurred within 2 weeks. He reported a history of vaping prior to the onset of each pneumothorax. The pneumothorax was resolved following pigtail chest tube placement. To the best of our knowledge, this is the first report to correlate recurrent pneumothoraces and vaping.

The potential adverse health effects of vaping have not been established, despite their growing use $[19,20]$. Previous case reports have suggested that vaping is associated with multiple pulmonary processes including exogenous lipoid pneumonia, bilateral pleural effusion, bronchiolitis, acute eosinophilic pneumonia, and acute hypersensitivity pneumonitis [13, 21-24]. Here, we report a correlation between vaping and recurrent spontaneous pneumothoraces for the first time.

We hypothesize that electronic cigarette use could potentially increase the risk of spontaneous pneumothorax through the action of both inhaled toxins and through physiologic mechanisms. In marijuana smokers, the increased risk of spontaneous pneumothorax is thought to be partially attributable to deep inhalation followed by a Valsalva maneuver during exhalation [25]. Repeated deep inhalation through a highly resistive device, such as a water pipe, creating a Muller maneuver, and generating large negative intrathoracic pressure, has also been proposed as a mechanism of spontaneous pneumothorax in marijuana smokers [26]. Given the airflow resistance of pod-based electronic cigarettes, such as the ones used by this patient, there is certainly potential for a vaping-related Muller maneuver driving spontaneous pneumothorax in this patient. In fact, airflow rates of vaping apparatuses vary from 20 to $102 \mathrm{~mL} / \mathrm{s}$ [27].

In addition to the potential physiologic risks of vaping, the nicotine and non-nicotine compounds inhaled in electronic cigarette smoke are associated with cellular injury and immune cell activation. Our patient reported using a JUUL device with mint flavored pods in the days leading to both pneumothorax episodes. In sampling multiple electronic cigarette delivery systems, JUUL pods were the only product to demonstrate in vitro cytotoxicity from both nicotine and flavor chemical content, in particular ethyl maltol [28]. The same study found that other marketed refill fluids can have a wide range of flavor concentrations, some as high as $362.3 \mathrm{mg} / \mathrm{mL}$. Furthermore, vape liquid pods may contain numerous other compounds and are known to provide unreliable nicotine delivery that is often inconsistent with the labeling [29]. These liquid pods also contain propylene glycol, 
which has been shown to induce airway epithelial injury and deep airway inflammation [30].

Changes in "puff topography" as defined by puff volume, airflow, and duration can alter the chemical compounds delivered to the patient [27]. Heating vape liquid can alter the nicotine and chemical flavor content delivered [28, 31]. The flavoring chemicals can generate low molecular weight carbonyl compounds, such as formaldehyde and acetaldehyde, which are known carcinogens. The production of carbonyl compounds can increase with increasing concentration of flavor compounds [31]. Many vape pods contain the flavoring chemicals diacetyl and 2,3-pentanedione [32]. These two specific compounds have been shown to directly alter the transcriptional profiles of primary human bronchial epithelial cells grown at air-liquid interface, phenotypically leading to impaired ciliogenesis [33]. Electronic cigarette use can alter gene expression in the innate immune system of the airways, leading to increased levels of enzymes implicated in tissue injury including matrix metalloproteinase-9 and elastase [34]. The effect of vaping on the transcriptional profile and wound healing properties of the pleura remains unknown. Developing a full understanding of what chemicals are inhaled by someone who vapes remains challenging.

Although our patient reported no history of cigarettes or smokeless tobacco use, he did report a history of occasional marijuana use. Although a correlation has been made between marijuana and spontaneous pneumothorax, its causality remains undetermined as most studies were presented as case reports or small case series [35-37]. In a 2017 case-control study, daily cannabis smoking combined with tobacco use increased the risk of spontaneous pneumothorax compared to tobacco smoking alone in males [35]. It is possible that the combination of marijuana and vaping share similar effects and pathophysiology (that is, carbon monoxide burden and carcinogen additives) contributing to an elevated risk of spontaneous pneumothorax. In addition, marijuana smoking increases squamous metaplasia, airway lesions, goblet and basal cell hyperplasia, and cell disorganization [38]. Pre-existing changes to the airway due to marijuana use could further contribute to the susceptibility of spontaneous pneumothoraces in chronic electronic cigarette users.

Since his second admission to our hospital with recurrent spontaneous pneumothoraces, he has quit vaping and remained event-free 1-month post-discharge. Thus, our case report of a young adult with recurrent pneumothoraces correlated with vaping, to the best of our knowledge, is the first case report to associate spontaneous pneumothorax and vaping. We hypothesize that compounds delivered through the electronic cigarette may induce an innate inflammatory response in the lung and possibly alter airway and pleural gene expression to impair wound healing. Furthermore, the Muller maneuver performed when vaping through devices with relatively low airflow and high resistance may contribute to large transmural pressures across the alveolus increasing the likelihood of developing pneumothorax. In individuals who may have pre-existing blebs, these etiologies might increase the risk of pneumothorax. Chronic marijuana smoking has been proposed to lead to increased bleb formation, although proof of causality has been difficult to establish $[39,40]$. It is possible that chronic vaping may also lead to bleb formation. Further studies are required to evaluate these hypotheses.

\section{Abbreviations \\ BMI: Body mass index; CT: Computed tomography; CXR: Chest x-ray; ED: Emergency Department}

\section{Acknowledgements}

The authors would like to thank the clinicians and nurses of the Emergency Department and Department of Medicine at Massachusetts General Hospital.

\section{Authors' contributions}

$A B, A J B, S M A, T K K, A L J, E E F$, and JMV provided care for the patient during hospitalization; AB, RAW, MBF, RAD, and JMV reviewed literature and prepared the manuscript. All authors read and approved the final manuscript.

\section{Funding}

This work was supported in part by a Ruth L. Kirschstein National Research Service Award T32 HL116275 from the NIH National Heart, Lung, and Blood Institute (to MBF).

\section{Availability of data and materials \\ Not applicable.}

\section{Ethics approval and consent to participate} Not applicable.

\section{Consent for publication}

Written informed consent was obtained from the patient for publication of this case report and accompanying images. A copy of the written consent is available for review by the Editor-in-Chief of this journal.

\section{Competing interests}

The authors declare that they have no competing interests.

\section{Author details}

${ }^{1}$ Department of Medicine, Harvard Medical School, 25 Shattuck Street, Boston, MA 02115, USA. ${ }^{2}$ Department of Medicine, Massachusetts General Hospital, 55 Fruit Street, Boston, MA 02114, USA. ${ }^{3}$ Division of Pulmonary and Critical Care, Massachusetts General Hospital, 55 Fruit Street, Boston, MA 02114, USA. ${ }^{4}$ Division of Infectious Disease, Massachusetts General Hospital, 55 Fruit Street, Boston, MA 02114, USA.

Received: 14 May 2019 Accepted: 1 August 2019

Published online: 09 September 2019

\section{References}

1. Henry M, Arnold T, Harvey J. BTS quidelines for the management of spontaneous pneumothorax. Thorax. 2003;58(Suppl 2):ii39-52.

2. Noppen M, Verbanck S, Harvey J, Van Herreweghe R, Meysman M, Vincken W, et al. Music: a new cause of primary spontaneous pneumothorax. Thorax. 2004;59(8):722-4.

3. de Menezes Lyra R. Etiology of primary spontaneous pneumothorax. J Bras Pneumol. 2016;42(3):222-6.

4. Luh SP. Review: diagnosis and treatment of primary spontaneous pneumothorax. J Zhejiang Univ Sci B. 2010;11(10):735-44.

5. Sadikot RT, Greene T, Meadows K, Arnold AG. Recurrence of primary spontaneous pneumothorax. Thorax. 1997;52(9):805-9. 
6. Tan J, Yang Y, Zhong J, Zuo C, Tang H, Zhao H, et al. Association between $\mathrm{BMI}$ and recurrence of primary spontaneous pneumothorax. World J Surg. 2017;41(5):1274-80.

7. Bense L, Eklund G, Wiman LG. Smoking and the increased risk of contracting spontaneous pneumothorax. Chest. 1987;92(6):1009-12.

8. Tschopp JM, Bintcliffe O, Astoul P, Canalis E, Driesen P, Janssen J, et al. ERS task force statement: diagnosis and treatment of primary spontaneous pneumothorax. Eur Respir J. 2015;46(2):321-35.

9. Cheng YL, Huang TW, Lin CK, Lee SC, Tzao C, Chen JC, et al. The impact of smoking in primary spontaneous pneumothorax. J Thorac Cardiovasc Surg. 2009;138(1):192-5.

10. Bhatnagar A, Whitsel LP, Blaha MJ, Huffman MD, Krishan-Sarin S, Maa J, et al New and emerging tobacco products and the nicotine endgame: the role of robust regulation and comprehensive tobacco control and prevention: a presidential advisory from the American Heart Association. Circulation. 2019; 139(19):e937-58. https://doi.org/10.1161/CIR.0000000000000669.

11. Zulkifli A, Abidin EZ, Abidin NZ, Amer Nordin AS, Praveena SM, Syed Ismai SN, et al. Electronic cigarettes: a systematic review of available studies on health risk assessment. Rev Environ Health. 2018;33(1):43-52.

12. Goniewicz ML, Boykan R, Messina CR, Eliscu A, Tolentino J. High exposure to nicotine among adolescents who use Juul and other vape pod systems ('pods'). Tob Control. 2018; https://doi.org/10.1136/tobaccocontrol-2018-054565.

13. Hua M, Talbot P. Potential health effects of electronic cigarettes: $A$ systematic review of case reports. Prev Med Rep. 2016;4:169-78.

14. Atkins $G$, Drescher $F$. Acute inhalational lung injury related to the use of electronic nicotine delivery system (ENDS). CHEST. 2015;148(4):83A.

15. Camus M, Gallois C, Marteau P. Ulcerative colitis and electronic cigarette: what's the matter? Am J Gastroenterol. 2014;109(4):608-9.

16. Kivrak T, Sunbul M, Durmus E, Dervisova R, Sari I, Yesildag O. Acute myocardial infarction due to liquid nicotine in a young man. Ther Adv Cardiovasc Dis. 2014;8(1):32-4.

17. Vannier S, Ronziere T, Ferre JC, Lassalle V, Verin M. Reversible cerebral vasoconstriction syndrome triggered by an electronic cigarette: case report. Eur J Neurol. 2015;22(5):e64-5.

18. MacDuff A, Arnold A, Harvey J. Management of spontaneous pneumothorax: British Thoracic Society pleural disease guideline 2010 Thorax. 2010;65(Suppl 2):ii18-31.

19. Jackler RK, Ramamurthi D. Nicotine arms race: JUUL and the high-nicotine product market. Tob Control. 2019; https://doi.org/10.1136/tobaccocontrol-2 018-054796.

20. Glauser W. New vaping products with techy allure exploding in popularity among youth. CMAJ. 2019;191(6):E172-e3.

21. Hureaux J, Drouet M, Urban T. A case report of subacute bronchial toxicity induced by an electronic cigarette. Thorax. 2014;69(6):596-7.

22. McCauley L, Markin C, Hosmer D. An unexpected consequence of electronic cigarette use. Chest. 2012;141(4):1110-3.

23. Thota D, Latham E. Case report of electronic cigarettes possibly associated with eosinophilic pneumonitis in a previously healthy active-duty sailor. J Emerg Med. 2014:47(1):15-7.

24. Sommerfeld CG, Weiner DJ, Nowalk A, Larkin A. Hypersensitivity pneumonitis and acute respiratory distress syndrome from e-cigarette use. Pediatrics. 2018;141(6) https://doi.org/10.1542/peds.2016-3927.

25. Miller WE, Spiekerman RE, Hepper NG. Pneumomediastinum resulting from performing Valsalva maneuvers during marihuana smoking. Chest. 1972; 62(2):233-4.

26. Hazouard E, Koninck JC, Attucci S, Fauchier-Rolland F, Brunereau L, Diot P. Pneumorachis and pneumomediastinum caused by repeated Muller's maneuvers: complications of marijuana smoking. Ann Emerg Med. 2001; 38(6):694-7.

27. Korzun T, Lazurko M, Munhenzva I, Barsanti KC, Huang Y, Jensen RP, et al. Ecigarette airflow rate modulates toxicant profiles and can lead to concerning levels of solvent consumption. ACS Omega. 2018;3(1):30-6.

28. Omaiye EE, McWhirter KJ, Luo W, Pankow JF, Talbot P. High Nicotine Electronic Cigarette Products: Toxicity of JUUL Fluids and Aerosols Correlates Strongly with Nicotine and Some Flavor Chemical Concentrations. Chem Res Toxicol. 2019:32(6):1058-69.

29. Hahn J, Monakhova YB, Hengen J, Kohl-Himmelseher M, Schussler J, Hahn $\mathrm{H}$, et al. Electronic cigarettes: overview of chemical composition and exposure estimation. Tob Induc Dis. 2014;12(1):23.

30. Chaumont M, van de Borne P, Bernard A, Van Muylem A, Deprez G, Ullmo J et al. Fourth generation e-cigarette vaping induces transient lung inflammation and gas exchanges disturbances: results from two randomized clinical trials. Am J Physiol Lung Cell Mol Physiol. 2019;316(5): L705-19.

31. Qu Y, Kim KH, Szulejko JE. The effect of flavor content in e-liquids on ecigarette emissions of carbonyl compounds. Environ Res. 2018;166:324-33.

32. Allen JG, Flanigan SS, LeBlanc M, Vallarino J, MacNaughton $P$, Stewart JH, et al. Flavoring chemicals in e-cigarettes: diacetyl, 2,3-pentanedione, and acetoin in a sample of 51 products, including fruit-, candy-, and cocktailflavored e-cigarettes. Environ Health Perspect. 2016;124(6):733-9.

33. Park HR, O'Sullivan M, Vallarino J, Shumyatcher M, Himes BE, Park JA, et al. Transcriptomic response of primary human airway epithelial cells to flavoring chemicals in electronic cigarettes. Sci Rep. 2019;9(1):1400.

34. Reidel B, Radicioni G, Clapp PW, Ford AA, Abdelwahab S, Rebuli ME, et al. Ecigarette use causes a unique innate immune response in the lung, involving increased neutrophilic activation and altered mucin secretion. Am J Respir Crit Care Med. 2018;197(4):492-501.

35. Hedevang Olesen W, Katballe N, Sindby JE, Titlestad IL, Andersen PE, Ekholm $\mathrm{O}$, et al. Cannabis increased the risk of primary spontaneous pneumothorax in tobacco smokers: a case-control study. Eur J Cardiothorac Surg. 2017;52(4):679-85.

36. Hancox RJ, Poulton R, Ely M, Welch D, Taylor DR, McLachlan CR, et al. Effects of cannabis on lung function: a population-based cohort study. Eur Respir J. 2010;35(1):42-7.

37. Shah A, Paramlal M. The importance of an illicit drug history in the evaluation of suspected spontaneous pneumothorax. BMJ Case Rep. 2011 2011 https://doi.org/10.1136/bcr.01.2011.3693.

38. Gong H Jr, Fligiel S, Tashkin DP, Barbers RG. Tracheobronchial changes in habitual, heavy smokers of marijuana with and without tobacco. Am Rev Respir Dis. 1987;136(1):142-9.

39. Johnson MK, Smith RP, Morrison D, Laszlo G, White RJ. Large lung bullae in marijuana smokers. Thorax. 2000;55(4):340-2

40. Aldington S, Williams M, Nowitz M, Weatherall M, Pritchard A, McNaughton A, et al. Effects of cannabis on pulmonary structure, function and symptoms. Thorax. 2007;62(12):1058-63.

\section{Publisher's Note}

Springer Nature remains neutral with regard to jurisdictional claims in published maps and institutional affiliations.
Ready to submit your research? Choose BMC and benefit from:

- fast, convenient online submission

- thorough peer review by experienced researchers in your field

- rapid publication on acceptance

- support for research data, including large and complex data types

- gold Open Access which fosters wider collaboration and increased citations

- maximum visibility for your research: over $100 \mathrm{M}$ website views per year

At $\mathrm{BMC}$, research is always in progress.

Learn more biomedcentral.com/submissions 